\title{
AS TRANSFORMAÇÕES MORFOLÓGICAS E FITOGEOGRÁFICAS DO ESTUÁRIO DO RIO SÃO MATEUS, LITORAL NORTE DO ESTADO DO ESPÍRITO SANTO, ENTRE 1970 E 2008.
}

\author{
Cláudia Câmara do Vale ${ }^{1}$ \\ Jurandyr Luciano Sanches Ross ${ }^{2}$
}

\begin{abstract}
Resumo: $O$ presente artigo é fruto de pesquisas realizadas no litoral norte do estado do Espírito Santo. O trabalho que ora se apresenta é parte da dissertação de Mestrado da primeira autora, complementado de pesquisas atuais. A proposta desta pesquisa foi analisar as modificações geomorfológicas e fitogeográficas ocorridas nos manguezais da foz do rio São Mateus no período de 1970 a 2008. Realizou-se levantamentos fitossociológicos dos manguezais, levantamento de dados fluviométricos, pluviométricos, sedimentológicos e dados do uso da terra da bacia do rio São Mateus. O resultado é a análise integrada desses dados, cujo objetivo principal foi considerar a correlação entre os processos naturais $e$ as atividades humanas e entender a evolução e a configuração do estuário e de seus elementos morfológicos e fitogeográficos, apoiada nos pressupostos metodológicos de Ab'Sáber (1969), Ross (1992) e Thom (1992). A correlação dos elementos e fatores, à luz da visão sistêmica foi fundamental para pesquisa.
\end{abstract}

Palavras-chave: Geomorfologia costeira; Ecossistema manguezal; Processos flúvio-marinhos

\section{Morphologic and Fitogeography Modifications of the São Mateus River Estuary, Northest Coast of the Espírito Santo State, Between 1970 and 2008}

\begin{abstract}
This article is about a lot of years of research developed in northeast of Espirito Santo state. This work is a part of Master Degree of the first author, complementado de pesquisas atuais. The proposal of this research was analyze the geomorphologic and fitogeographical of the mangroves which that take place on São Mateus River estuary between 1970 a 2008. Realizou-se levantamentos fitossociológicos dos manguezais, levantamento de dados fluviométricos, pluviométricos, sedimentológicos e dados do uso da terra da bacia do rio São Mateus. The result is the integrated analyze of this datas, which main objective was consider the correlations between natural and anthropogenic processes and understand the evolution and configuration of the estuary and its fitogeographic and morphologic elements, supported in methodologies presupposes of Ab'Sáber (1969) and Ross (1992). The correlation of these elements and factors from a system view was fundamental for this research.
\end{abstract}

Keywords: Coastal geomorphology; Mangroves ecosystems; Fluvial and marine processes

\footnotetext{
'Professora Doutora do Departamento de Geografia da Universidade Federal do Espírito Santo. Endereço Postal: Avenida Fernando Ferrari, 514 - Campus de Goiabeiras - Vitória (ES). CEP 29000-900 E-mail: camaravale@gmail.com Parte desta pesquisa refere-se à dissertação de mestrado que teve apoio financeiro da CAPES entre os anos de 1995 a 1999.

${ }^{2}$ Professor Titular do Departamento de Geografia da Universidade de São Paulo. Endereço Postal: Avenida Prof. Lineu Prestes, 338. Cidade Universitária. São Paulo. CEP 05508-000. E-mail: juraross@usp.br
} 


\section{INTRODUÇÃO}

A geografia abrange uma complexidade de interações entre aspectos naturais e sociais, que obriga o geógrafo estudá-los em conjunto, de modo que a todos seja atribuída igual importância para compreender as relações sociedade-natureza, bem como para propor medidas que possibilitem a exploração dos recursos naturais visando sua utilização sem, contudo, levá-los à exaustão.

Dentre os propósitos da Geografia se destaca o planejamento regional, que passou a ter grande importância, sobretudo na década de 1970, em função dos impactos exercidos pelo desenvolvimento industrial. Nessa fase, a ocupação rápida e desordenada do espaço é observada tanto nas grandes e pequenas cidades quanto no campo. Problemas como o esgotamento de jazidas, a intensificação da destruição das florestas, a erosão das encostas nas áreas urbanas e rurais, o lançamento de resíduos industriais e de dejetos nos rios e na costa, são apenas alguns exemplos que contribuem para a perspectiva de uma qualidade de vida humana fora dos padrões mínimos aceitáveis.

Dentre os espaços que se encontram densa e desordenadamente ocupados, no âmbito nacional, destaca-se a costa, onde se concentram grandes capitais e cidades balneárias. Definido como uma zona de múltiplos usos (BRASIL, 1996), no litoral do Brasil é possível encontrar diversas formas de ocupação e uso da terra, manifestados por meio das diferentes atividades humanas.

As tribos indígenas e as populações tradicionalmente pescadoras e coletoras compõem um mosaico com cidades industriais e metrópoles dotadas de todos os aparatos da modernidade. Evidentemente que a história da ocupação do espaço litorâneo brasileiro retrata como as tribos indígenas e as populações tradicionais quase sucumbiram, cedendo lugar aos aglomerados urbanos, de modo que tal mosaico se apresente, atualmente, em peças espacialmente desproporcionais.

Ab'Sáber (1990) e Dean (1997) concordam que a ocupação da faixa litorânea brasileira por grupos humanos, ao longo da história, foi impulsionada por diferentes motivos e dotada de componentes culturais muito diversos. Para Dean (1997:42) os primeiros grupos humanos, provindos do interior do continente sul-americano, tangidos pelo declínio dos grandes animais de caça, mudaram-se para a margem das baixadas do continente. De acordo com o autor, "Grande parte da costa era protegida por recifes ou bancos de areia, que permitiu a formação de estuários de maré, verdadeiros lagos de acumulação de nutrientes arrastados 
por rios e riachos. Ali os exploradores encontraram pântanos de mangue e, presas ao manguezal, ostras de mangue. Uma economia maravilhosamente conveniente - quase nenhuma energia ou técnica eram necessárias para colher proteína das árvores!".

A costa brasileira experimentou vários ciclos de ocupação e exploração de seus recursos, desde os índios Tupi-guaranis, caçadores e coletores, passando pela implantação de feitorias pelos portugueses, pela introdução e expansão da cultura da cana-de-açúcar no Nordeste Oriental e pela bananicultura no Sudeste, saltando para o grande impulso imobiliário que vem utilizando a imensa costa para especulações de todos de tipos.

Decorrentes dos ciclos econômicos ocorridos no Brasil, sobretudo durante o Período Colonial, podemos citar a implantação das cidades litorâneas, como por exemplo, Recife, Olinda, Salvador, Vitória, Rio de Janeiro, Santos e São Vicente.

Praticamente as demais extensões do litoral permaneceram isoladas ou pouco ocupadas durante muito tempo, constituindo áreas de refúgios de tribos indígenas e de escravos fugidios, que acabariam por instalar pequenas comunidades, cujos hábitos rudimentares de subsistência, concedem um forte vínculo dessas populações tradicionais que, ainda hoje, estão presentes em algumas porções da costa brasileira.

Em função da mudança da economia, segundo Brasil (1996:27) "[...] vários dos ramos industriais importantes, em instalação, vão sofrer uma grande dependência do abastecimento de insumos externos, o que condiciona sua localização à proximidade com sítios portuários. [...] pode-se dizer que os setores altamente ligados ao transporte marítimo, ou pela exportação da produção, vão localizar suas plantas industriais prioritariamente na zona costeira."

Nas proximidades das metrópoles litorâneas inicia-se um processo de ocupação, cuja estratégia especulativa força os antigos habitantes da costa a venderam seus terrenos afim de produzir espaços fundiário-imobiliários ${ }^{1}$. Tal fato provoca não só a descaracterização das comunidades tradicionais, gerando um grande conflito social, como também uma gama de impactos negativos aos recursos naturais costeiros, de cunho ambiental.

A despeito dos fatos expostos acima e segundo Muehe (1994), a preocupação de planejar racionalmente a ocupação e o uso de espaço costeiro é relativamente recente no Brasil. Os constantes problemas resultantes de interferência, direta e indireta, no balanço de

\footnotetext{
${ }^{1}$ As etapas de ocupação da zona costeira brasileira estão muito bem descritas no Macrozoneamento da Zona Costeira (BRASIL, 1996) onde consta que as populações remanescentes vão alojar-se no espaço urbano litorâneo exatamente nas áreas deixadas sem uso pelas outras atividades, que geralmente são áreas de grande vulnerabilidade e/ou de proteção ambiental, o que nos lembra as encostas íngremes e as zonas sujeitas a inundações e as áreas de defesa de mananciais ou os manguezais.
} 
sedimentos costeiros, do avanço da urbanização sobre áreas que deveriam ser preservadas, mostram que ainda é longo o caminho entre intenção e realização.

Dentre os ecossistemas que compõem os ambientes litorâneos destaca-se o manguezal, representando um dos mais ricos sistemas costeiros, de grande importância geológicogeomorfológica, ecológica, sócio-econômica e cultural.

Todavia, devido a sua localização em áreas litorâneas, abrigadas e protegidas, os manguezais estão sujeitos à destruição provocada pelos processos de expansão urbana, industrial e portuária, realizada de maneira inconseqüente e desordenada, principalmente nos países subdesenvolvidos. As intervenções antrópicas mais freqüentes que afetam diretamente os manguezais são aterros, lançamento de lixo e esgoto, corte indiscriminado da madeira, retirada da casca de Rhizophora mangle para aproveitamento do tanino, pesca predatória, construção de tanques de criação de camarão, dentre outros.

Entretanto, considerando as forças e processos que originam e mantêm as áreas estuarinas, tais como a dinâmica costeira e os processos fluviais locais, podem ser observadas, ainda, as alterações ditas "naturais", tais como erosão e sedimentação aceleradas sobre as áreas de manguezais. As áreas estuarinas, caracterizadas pela forte interação entre os processos continentais e marinhos, estão sujeitas às ações dos elementos costeiros, tais como ondas e marés, bem como às ações dos elementos continentais, como variações na descarga de sedimentos carreados pelos rios e pela precipitação, constituindo áreas extremamente instáveis. A instabilidade e o funcionamento dinâmico dessas áreas são, em parte, devido aos ajustamentos naturais, resultando em mudanças graduais da configuração e articulação costeira ao longo do tempo, e em parte induzidas pela interferência humana.

Dentro desse contexto, o estuário do rio São Mateus, localizado na cidade de Conceição da Barra (Figura 1), caracteriza-se pela ocorrência de processos flúvio-marinhos que vêm acarretando sérios problemas de erosão na sua principal praia, denominada Bugia, localizada à margem esquerda, além de grandes alterações fisionômicas no bosque de mangue de toda sua foz, as quais se devem ora a processos erosivos ora a processos de acelerada sedimentação. Em função dessas alterações morfológicas, a cidade de Conceição da Barra enfrenta sérios problemas sociais e econômicos, relacionados à destruição de dezenas de residências, bem como dificuldade de navegação das embarcações pesqueiras. 


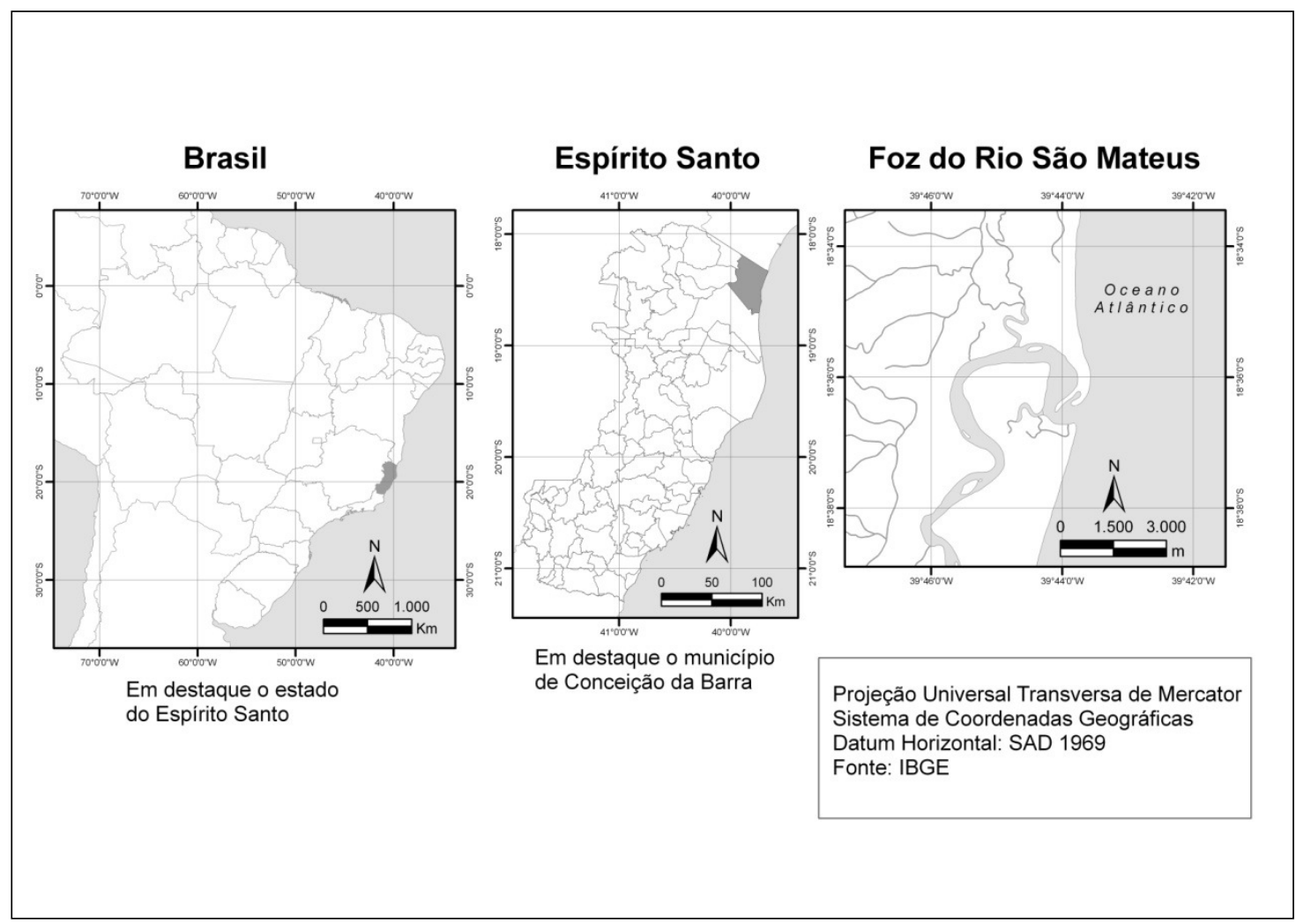

Figura 1 - Localização do estuário do rio São Mateus no contexto regional e estadual.

A origem dos processos erosivos e sedimentares sobre as áreas de manguezais é, muitas vezes, atribuída à elevação do nível médio do mar, podendo este ser um fenômeno acelerado pelas atividades humanas. Todavia, a despeito da crescente preocupação, tanto da comunidade científica quanto da sociedade, com possíveis níveis de mares mais elevados, deve-se buscar, inicialmente, compreender as causas mais evidentes e mais próximas que podem provocar as modificações na linha de costa, como por exemplo, a ocupação desordenada da costa e, ultrapassando os limites conceituais desse setor, compreender como se dá o uso da terra ao longo da bacia hidrográfica como um todo. Portanto, deve-se considerar a correlação entre os processos naturais, inerentes ao ambiente físico e as atividades humanas, ao tentar entender a evolução e a configuração de um estuário e de seus elementos fitogeográficos.

Neste trabalho serão apresentados os resultados entre a relação da descarga fluvial na foz do rio São Mateus, a precipitação ao longo de sua bacia e os processos geomorfológicos flúvio-marinhos que geram como resposta, as alterações sobre os manguezais. 


\section{MATERIAIS E MÉTODOS}

Realizou-se um amplo levantamento bibliográfico, cartográfico e fotográfico, assim como de cartas sinópticas, cartas náuticas e tábuas de marés da área de Conceição da Barra, mapa de uso da terra, além do levantamento dos dados pluviométricos e fluviométricos das estações localizadas na área da bacia do rio São Mateus.

Para a análise da foz do rio São Mateus foi realizada interpretação das fotografias aéreas de 1970, 1991 e 1997, nas escalas 1:25:000, 1:30.000 e 1:8.000, respectivamente. As fotografias aéreas de 2008 estão sendo atualmente utilizadas para uma pesquisa de mestrado realizada no Curso de Pós-Graduação da Ufes, cujo intuito é acompanhar a dinâmica estuarina da foz do rio São Mateus e o comportamento da vegetação.

Ao longo do estuário foram demarcados pontos para levantamento dos dados bióticos e abióticos dos manguezais. A metodologia empregada para o levantamento dos dados bióticos e abióticos dos manguezais foi aquela estabelecida por Schaeffer-Novelli e Cintrón (1986). Posteriormente, tratou-se e organizou-se os dados bióticos e abióticos do manguezal de cada parcela realizada ao longo dos transectos demarcados nos manguezais, além dos mapeamentos da foz apresentados neste trabalho.

Foram elaborados gráficos sobre a precipitação e descarga fluvial abrangendo diferentes períodos em função da disponibilidade de dados existentes em cada estação. 0 detalhamento dos dados bióticos e abióticos dos manguezais não serão contemplados nesse artigo.

\section{RESULTADOS E DISCUSSÕES}

Compondo depósitos quaternários do Espírito Santo, os manguezais da bacia do rio São Mateus cobrem uma área de 10,82 km² (VALE e FERREIRA, 1998), sendo mais exuberantes no estuário inferior ou marinho, onde mangues, que compõem bosques mistos, estão subdivididos em bosques altos, médios e baixos. Os bosques altos apresentam altura aproximada de 15 metros, os bosques médios têm altura de 7 metros, enquanto os baixos apresentam-se inferior a 7 metros de altura. As espécies vegetais predominantes são Rhizophora mangle e Laguncularia racemosa. A primeira domina a franja dos bosques enquanto a segunda ocorre mais para o interior, compondo bosques mistos. A ocorrência de Avicennia schaueriana é também significativa, sobretudo próximo às áreas de restinga. $\mathrm{A}$ 
espécie Avicennia germinans é a de menor freqüência, ocorrendo principalmente no estuário médio e superior.

No estuário ocorrem os três tipos fisiográficos da classificação proposta por Lugo e Snedaker (1975), ou seja, franja, ribeirinho e bacia. A ocorrência e repetição dos processos, ora sedimentares ora erosivos, conduziram a análise e a compartimentação da área de manguezais estudada em três setores distintos: o setor 1 que abrange os transectos 1 e 2; o setor 2 abrangendo os transectos 3 e 4 e, finalmente o setor 3 abrangendo os transectos 5, 6 e 7 (Figura 2).

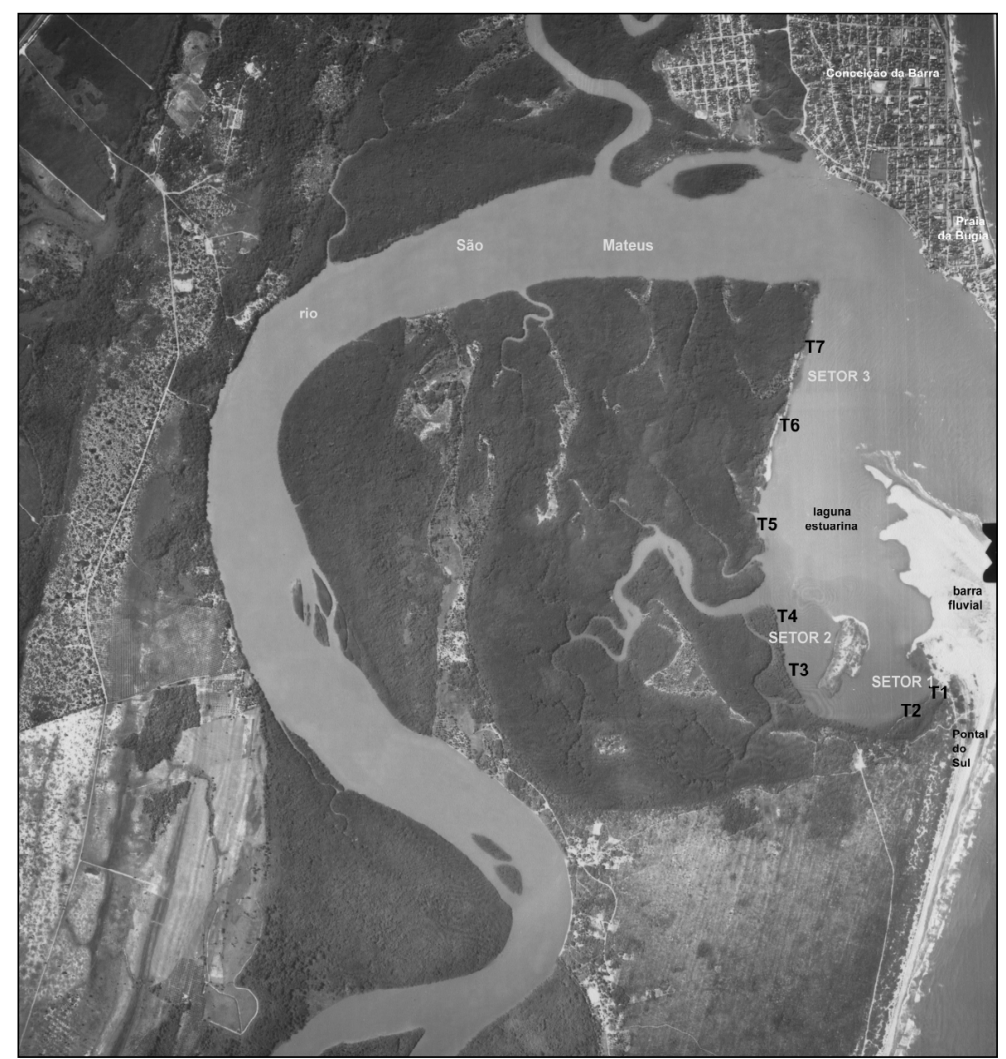

Figura 2 - Foz do rio São Mateus apresentando o posicionamento dos transectos $(\mathrm{T} 1, \mathrm{~T} 2)$ e a setorização da análise. Foto: Maplan, 2008.

As modificações geomorfológicas e fitogeográficas apresentadas pela foz do rio São Mateus e adjacências, investigadas nessa pesquisa, referem-se a um período de 38 anos, compreendido entre os anos de 1970 e 2008.

Em 1970 a foz do rio São Mateus apresentava nítidos bancos sedimentares emersos, feições provavelmente resultantes da maré vazante. Dois bancos de sedimentação também eram 
visíveis no interior do que chamamos de laguna estuarina ${ }^{2}$. Nessa data, o bosque de mangue localizado à margem direita da foz apresentava-se bastante exuberante. À margem esquerda da foz, quase paralela à linha de costa, existia uma barra fluvial com aproximadamente um quilômetro de extensão e 375 metros de largura. Essa feição, sem ocupação humana, encontrava-se vegetada, apresentando, inclusive, um pequeno cultivo de cocos (Figura 3).

Aparentemente, nessa época, não ocorriam, ainda, os complexos processos de erosão e sedimentação acelerados sobre o bosque de mangue à margem direita, nem a erosão sobre a praia da Bugia.

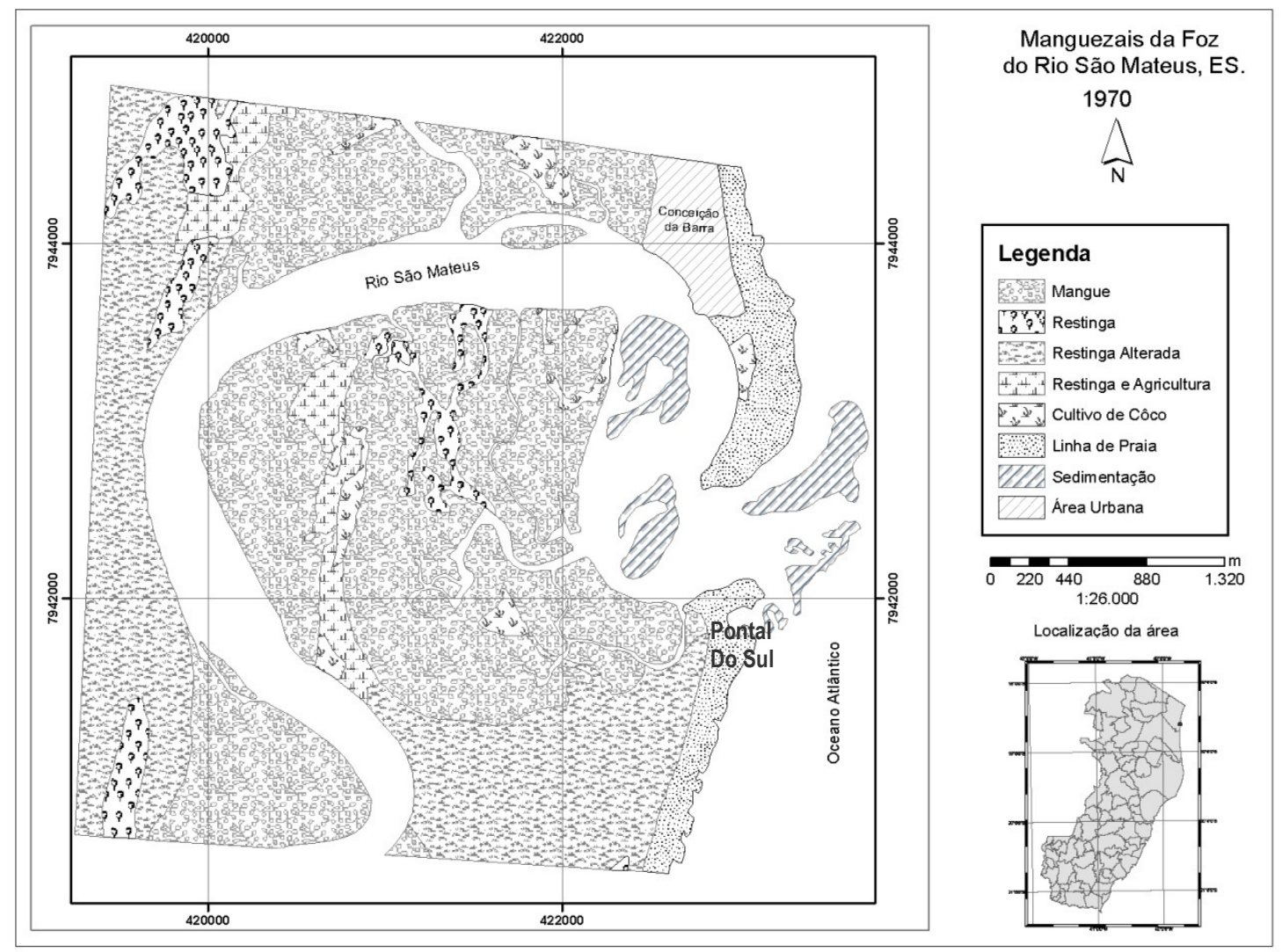

Figura 3 - Mapeamento da foz do rio São Mateus em 1970. Organizado por Vale em 2009.

Em 1991 a situação da foz apresentava-se completamente diferente. Dos dois bancos de sedimentação, que em 1970, afloravam na "laguna estuarina", apenas um era observado, com fisionomia muito modificada e em processo de colonização por mangues. $O$ restante da franja apresentava uma diminuição da área de manguezal (Figura 4). À margem direita, bem próxima ao Pontal do Sul, por exemplo, uma área de $650.000 \mathrm{~m}^{2}$ de manguezal havia

\footnotetext{
${ }^{2}$ Entende-se por "laguna estuarina" o corpo hídrico que se encontra semi-fechado na foz do rio São Mateus que mantém comunicação com o mar.
} 
desaparecido. A barra fluvial, à margem esquerda da foz, quase totalmente ocupada pela população local, alongava-se para o interior da laguna estuarina por mais 800 metros, ficando, portanto com aproximadamente dois quilômetros de extensão e 120 metros de largura, apresentando colonização por vegetação halófila-psamófila na extremidade.

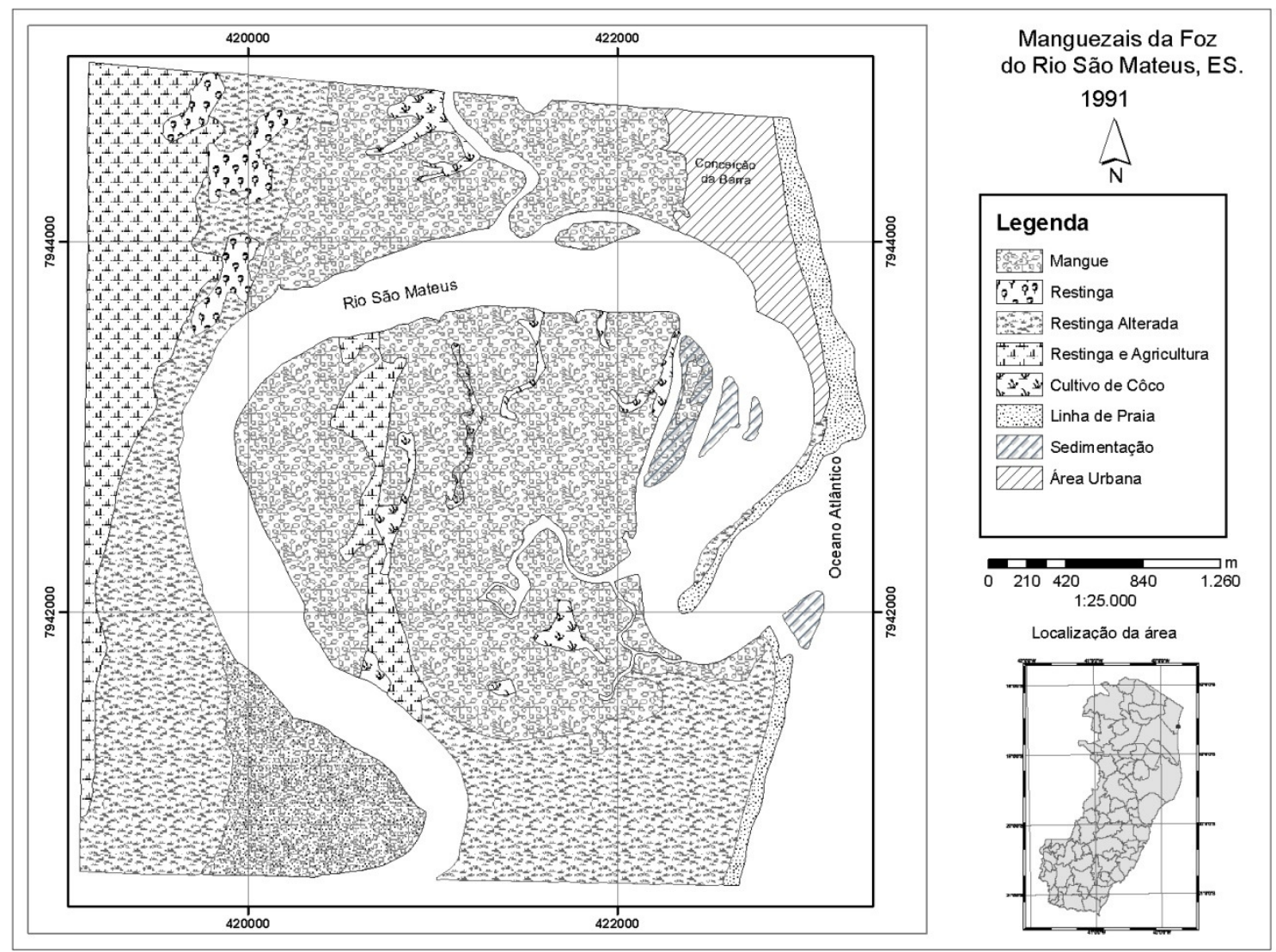

Figura 4 - Mapeamento da foz do rio São Mateus em 1991. Organizado por Vale em 2009.

A partir de 1993, quando se iniciaram os trabalhos de campo, observou-se que o processo de erosão sobre a praia da Bugia mostrava-se perceptível e ameaçava destruir um trecho da cidade, localizado à margem esquerda da desembocadura do rio São Mateus. Na margem direita da foz, próximo à linha de praia, os processos flúvio-marinhos resultavam na supressão de uma faixa de manguezal que visivelmente estava sofrendo sedimentação acelerada, soterrando o sistema radicular e provocando o tombamento dos indivíduos ainda vivos (Setor 1 da figura 2). Nessa época, sobre esse trecho de sedimentação arenosa, já se verificava a invasão da vegetação psamófila, como Ipomea pes-caprae, em um claro processo de sucessão (Figura 5). 
Observou-se também que a barra fluvial que, em 1991, apresentava-se alongada, havia rompido, restando apenas um banco de sedimentação bem desenvolvido, com vegetação psamófila, herbáceo-arbustiva.

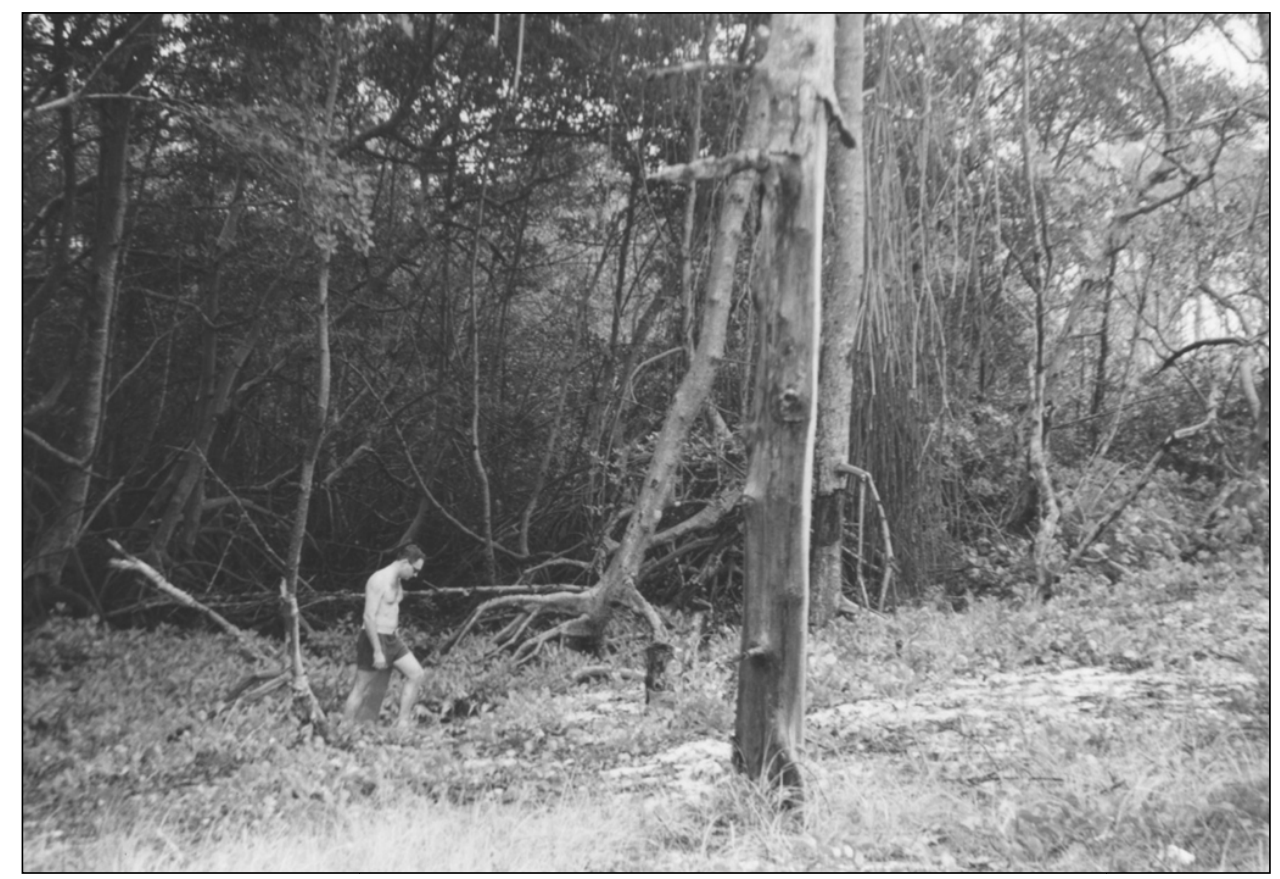

Figura 5 - Trecho do bosque de mangue denominado de setor 1, abrangendo os transectos 1 e 2, onde observa-se a sedimentação do sistema radicular do mangue e a invasão por espécies psamófilas. Fotografia: Acervo particular de Claudia Câmara do Vale.

Em 1997 a configuração da foz continuava a se alterar (Fig. 6). O processo de erosão, à margem esquerda, destruiu grande parte do que havia restado da barra fluvial rompida entre 1991 e 1997, atingindo arruamentos e edificações na praia da Bugia. O banco de areia, resultante do rompimento, permanecia no interior da "laguna estuarina", apresentando pequenas alterações morfológicas. Todavia o desenvolvimento da vegetação sobre esse banco era notório. A margem direita apresentava agora uma barra fluvial bem desenvolvida que, juntamente com o banco acima mencionado, quase isolou a laguna estuarina. $O$ bosque de mangue localizado nesse lado da foz apresentava-se em franco processo de expansão. Por outro lado, o banco de sedimentação remanescente, que em 1991 estava sendo colonizado por mangues, apresentava-se, em 1997, com dimensões menores, sobre o qual ainda persistia um pequeno bosque tipo ilhote, com indivíduos jovens. O trecho da franja, em frente a esse mangue ilhote, bem como em direção ao Pontal do Sul, antes da laguna estuarina, apresentava perda de área de manguezal. 
Por meio da interpretação das três séries de fotografias aéreas, bem como pelas observações de campo sistemáticas ao longo de cinco anos, pode-se perceber claramente que ocorreram e ocorrem processos de erosão e sedimentação acelerados que, ora destruíam trechos do bosque de mangue, ora possibilitavam sua expansão. Por outro lado, se intensificava a erosão sobre a praia da Bugia, à margem esquerda, e crescia a barra fluvial, à margem direita.

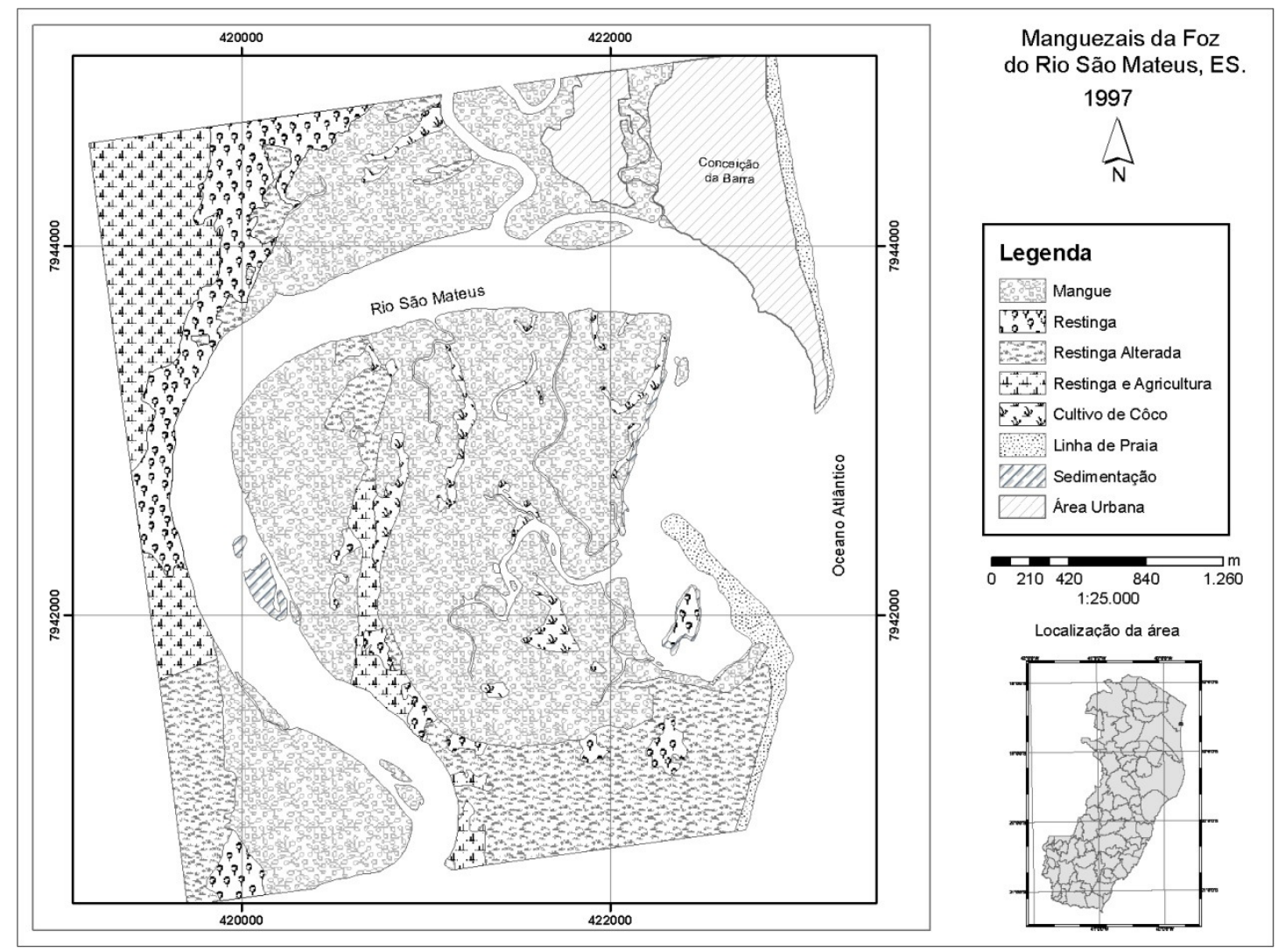

Figura 6 - Mapeamento da foz do rio São Mateus em 1997. Organizado por Vale em 2009.

A dinâmica que a foz do rio São Mateus apresenta nos obriga a refletir sobre os diversos elementos que interagem em uma área estuarina, tais como os elementos climáticos, hidrográficos, oceanográficos, fitogeográficos e de uso da terra, que tornam esses ambientes naturalmente instáveis.

Modificações de diferentes magnitude e freqüência dos processos geomórficos são inevitáveis em qualquer área. Todavia, está-se diante de alterações muito rápidas, tanto no tempo quanto no espaço. Diante dos fatos constatados emergem algumas questões. Que 
fatores preponderantes poderiam explicar tais modificações? Esses processos seriam resultantes de ações naturais ou antrópicas?

\section{Análise dos dados fluviométricos e pluviométricos}

A correlação entre os dados pluviométricos e fluviométricos apresentam significativas correlações que podem ser associadas ao comportamento da foz do rio São Mateus na maior parte do período analisado nessa pesquisa.

Para a estação pluviométrica de São Mateus a precipitação média anual para o período 1971 a 1995 é de 1272,0 mm. De 1986 a 1989 a precipitação média apresenta uma queda de 24,6 \%, ficando em torno de $958 \mathrm{~mm}$, isto é, $313,3 \mathrm{~mm}$ a menos que a média para o período de 1971 a 1995. Infelizmente os dados para os anos de 1990 e 1991, para essa estação, estão incompletos e não puderam ser utilizados nessa interpretação. Todavia, na figura 7, observase que o ano de 1992 apresenta uma elevação da precipitação em torno de 59\% em relação à precipitação média para o período de 26 anos, ficando em torno de $2022 \mathrm{~mm}$. Quando comparamos os dados pluviométricos da estação de São Mateus com os dados das outras duas estações encontramos situações semelhantes para o mesmo ano (Figuras 8 e 9).

Em 1991 e 1992, a exemplo do pode ser verificado para a estação de Ecoporanga (Figura 8), verifica-se uma acentuada elevação dos índices pluviométricos na estação de Boa Esperança. Desse modo, em 1991 a precipitação foi de 1284,4 mm e em 1992, 1733,2 mm, isto é, 34\% e $81 \%$, respectivamente, a mais que a média para o período demonstrado para as duas estações.

Com relação aos dados fluviométricos, que se referem apenas às descargas médias anuais nas estações localizada ao longo da bacia, não foram realizados cálculos das curvas-chaves, pois a intenção é demonstrar apenas a correlação da precipitação com o aporte de água na foz nos períodos acima enfatizados.

A figura 10 representa o conjunto de gráficos das descargas médias anuais de quatro das sete estações localizadas ao longo da bacia. Analisando o conjunto dos gráficos das localidades apresentadas percebe-se uma diminuição acentuada da descarga entre os anos de 1986 a 1990. Por outro lado, em 1991 verifica-se uma elevação nas descargas para as estações de Córrego da Boa Esperança, Barra do Rio Preto, São José da Cachoeira Grande e Boca da Vala. 


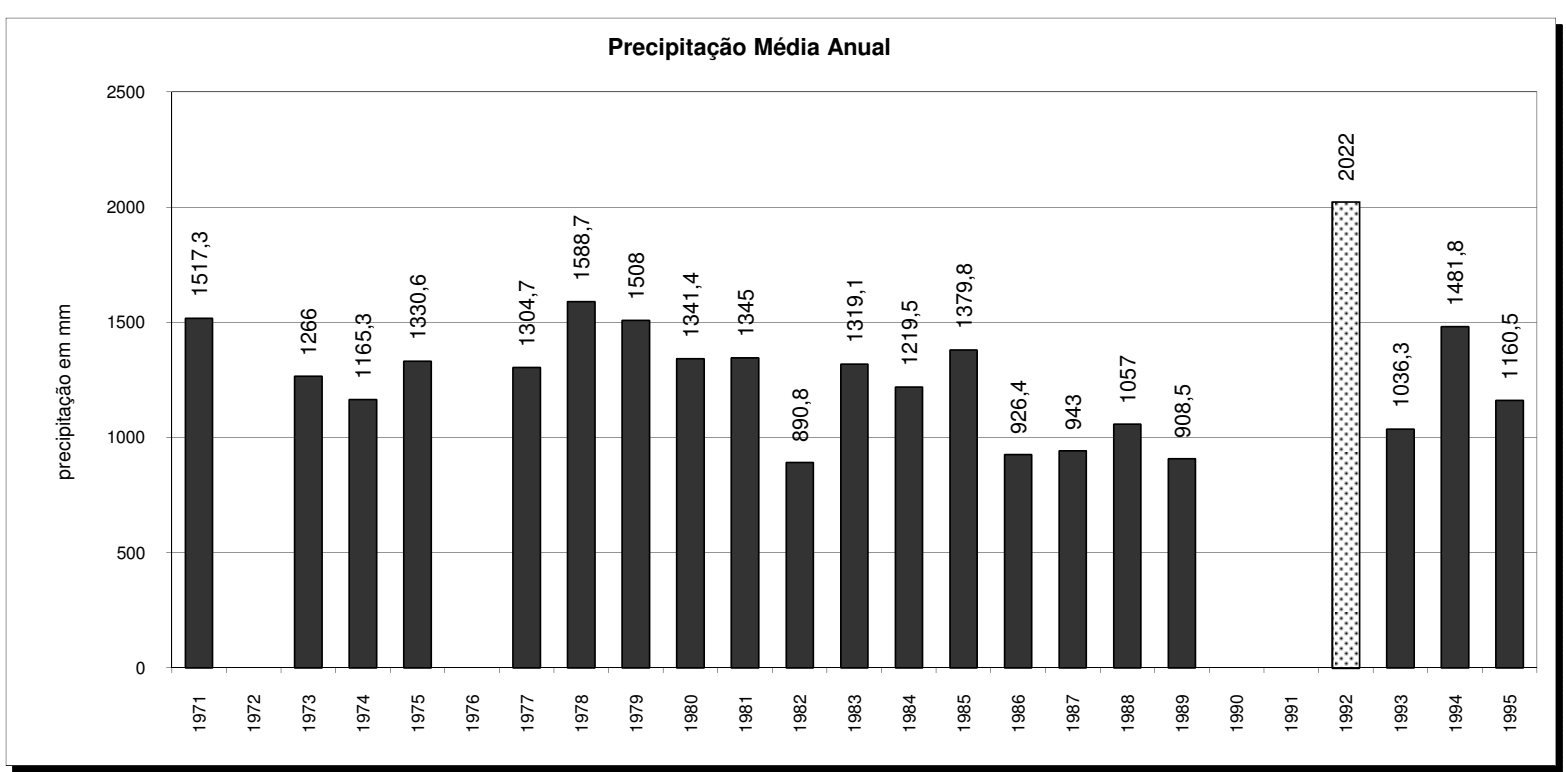

Figura 7 - Dados pluviométricos da Estação Meteorológica de São Mateus (ES) entre os anos 1971 a 1995. Fonte: Vale, 1999.

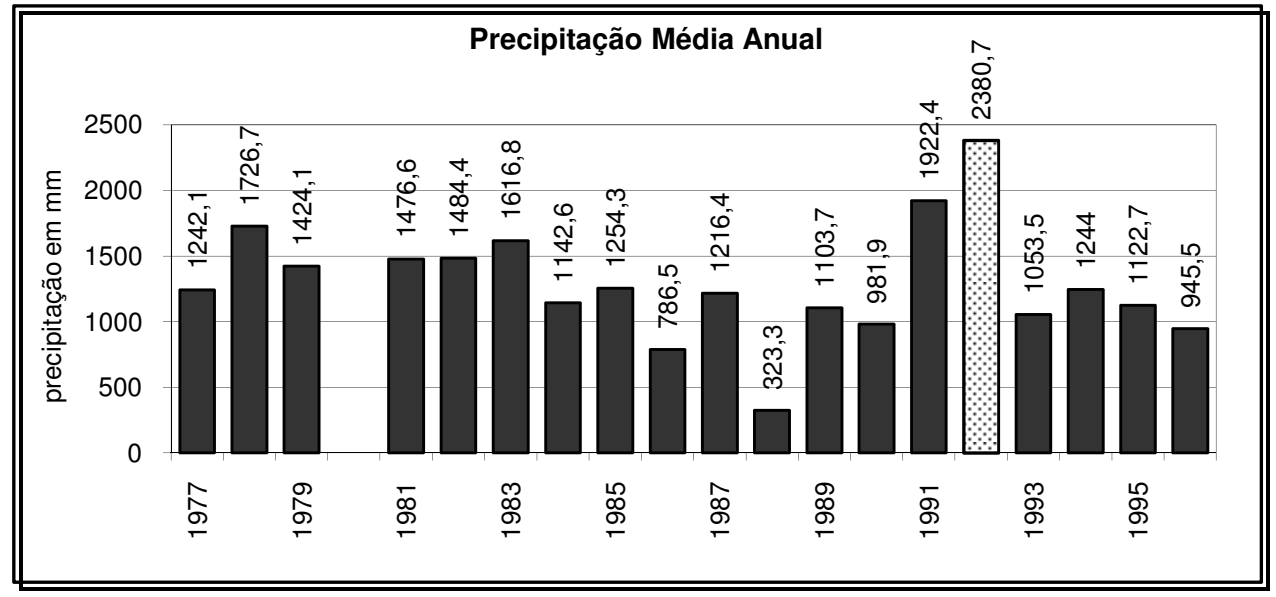

Figura 8 - Dados pluviométricos da Estação Meteorológica de Ecoporanga (ES) entre os anos de 1976 a 1996. Fonte: Vale, 1999.

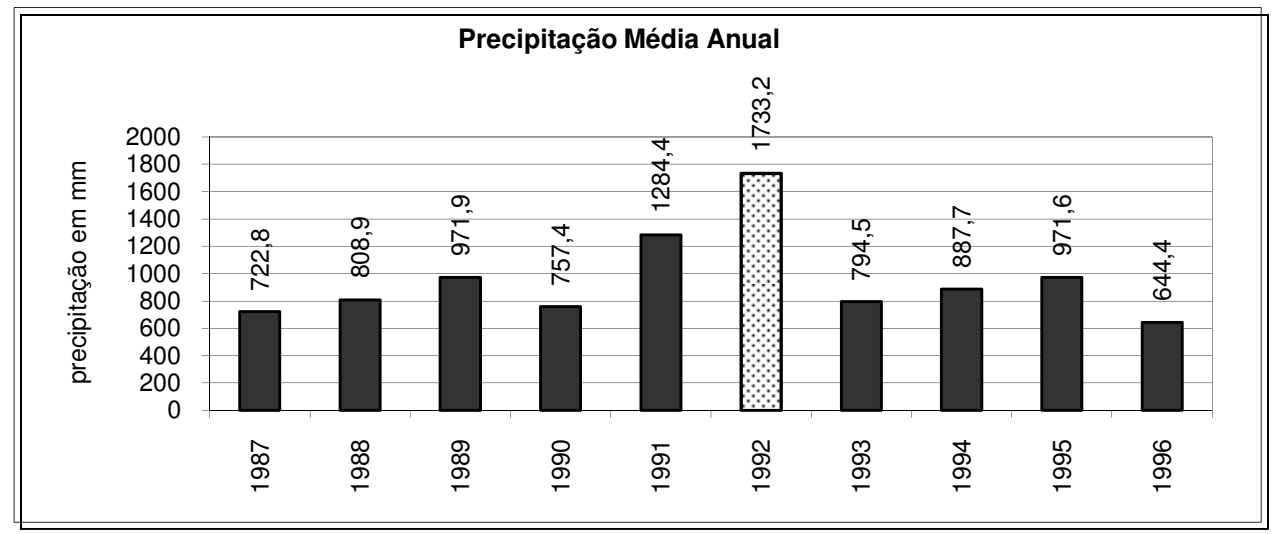

Figura 9 - Dados pluviométricos da Estação de Boa Esperança (ES) entre os anos de 1987 a 1996. Fonte: Vale, 1999. (Modificada) 
A correlação entre os dados pluviométricos e fluviométricos da bacia permite fazer interessantes considerações a respeito da configuração da foz do rio São Mateus e dos processos geomórficos que ocorreram e ocorrem nos últimos anos.

De 1986 a 1990, conforme mostram os gráficos, verifica-se diminuição da pluviosidade e, conseqüentemente, das descargas em toda a bacia.

Segundo Tucci (1993:40), "A bacia hidrográfica é uma área de captação natural da água da precipitação que faz convergir os escoamentos para um único ponto, o exutório.". Partindo dessa afirmação podemos entender que existe uma relação de causa e efeito entre a entrada, ou volume da água precipitado, e a saída, ou volume de água e sedimentos escoados, que pode se manifestar por meio das diversas configurações apresentadas pela foz ao longo do tempo.

Parece que em 1970 o fluxo fluvial, junto à desembocadura, apresentava maior descarga que em 1991, o que poderia explicar, em parte, o diferente comportamento da barra fluvial nas duas data acima mencionadas.

Em 1970 o fluxo fluvial parece desempenhar o papel de um "molhe hidráulico", retendo parte dos sedimentos transportados pela corrente de deriva litorânea que, nesse trecho do litoral brasileiro ocorre, predominantemente, de norte para sul (MARTIN et al., 1993).

Segundo Martin et.al. (1993:24), "Em determinadas condições, o fluxo fluvial de água junto à desembocadura de um rio poderá constituir um obstáculo, que tenderá a bloquear o transporte das areias do mesmo modo que um molhe artificial.[...]. Como resultado, os sedimentos ficarão retidos de encontro ao molhe, fazendo com que a linha de costa a barlamar dessa estrutura prograde rapidamente. A sotamar, a corrente de deriva litorânea continua atuante, removendo os sedimentos e provocando o avanço do mar por erosão da linha de costa.".

Em 1991 a condição de "molhe", exercida pelo fluxo fluvial numa época de maior descarga, parece inexistir. A barra fluvial à esquerda da foz não só está mais estreita como mais alongada para o interior da laguna estuarina. Como se a diminuição do fluxo fluvial tivesse permitido o entulhamento da foz pelos sedimentos transportados pela corrente de deriva litorânea e pela própria descarga de sedimentos fluviais, agora em menor quantidade.

Sobre a competência, capacidade e carga de sedimento transportada, Suguio e Bigarella (1990:29) afirmam que "a relação da seção do canal com a velocidade de fluxo determinará 
o tamanho máximo do material que pode ser movido (competência do rio) e o volume de carga transportada (capacidade do rio). Ambas dão idéia quantitativa de trabalho das correntes fluviais."

De acordo com Martin et.al. (1993:24) "Em período de baixa descarga fluvial, o obstáculo representado pelo fluxo fluvial irá praticamente desaparecer e conseqüentemente, a meiacúspide construída a barlamar, na fase anterior, experimentará acelerado processo de erosão. Os sedimentos erodidos serão deslocados para sotamar, originando um esporão arenoso que tenderá a obstruir parcialmente a foz."

A obstrução parcial apresentada pela foz em 1991, numa época de baixa descarga fluvial, ocasionou o desvio do fluxo que não conseguiu romper o obstáculo representado pela barra fluvial. O desvio do canal em direção sul, bem como a diminuição do raio hidráulico, explicado provavelmente pela dinâmica da água corrente ocasionou o trabalho de erosão e/ou sedimentação responsável, possivelmente, pelo desaparecimento dos $650.000 \mathrm{~m}^{2}$ do bosque de mangue, já referido anteriormente.

Observando o mapeamento de 1991 (Figura 4), parece ter havido mesmo uma erosão desse trecho, já que se observou, por meio de fotointerpretação e de observação em campo, um nítido degrau entre a vegetação de mangue e o leito fluvial. Entre 1993 e 1994, verificou-se uma sedimentação acelerada sobre o mangue remanescente ao acima mencionado, onde indivíduos de Rhizophora mangle e Lagunculeria racemosa apresentavam-se parcialmente soterrados por sedimentos de origem flúvio-marinha (Figura 5). Possivelmente, o que observávamos na época fosse decorrente de uma nova situação morfológica então apresentada pela foz.

Desse modo, ainda correlacionando escoamento e precipitação, essa nova configuração da foz pode ser explicada, pelo menos em parte, por uma elevação marcante nos índices pluviométricos e, conseqüentemente, na descarga fluvial que ocorreu entre 1991 e 1992, conforme demonstram os gráficos.

A barra fluvial não suportou a força do fluxo do rio e rompeu-se, ocasionando uma nova situação morfológica da foz que evoluiu para a que observamos no mapeamento de 1997 da foz, representado na figura 6. Como se percebe, houve inversão da posição da barra fluvial e da seção principal do canal, que passou a se localizar ao norte. 

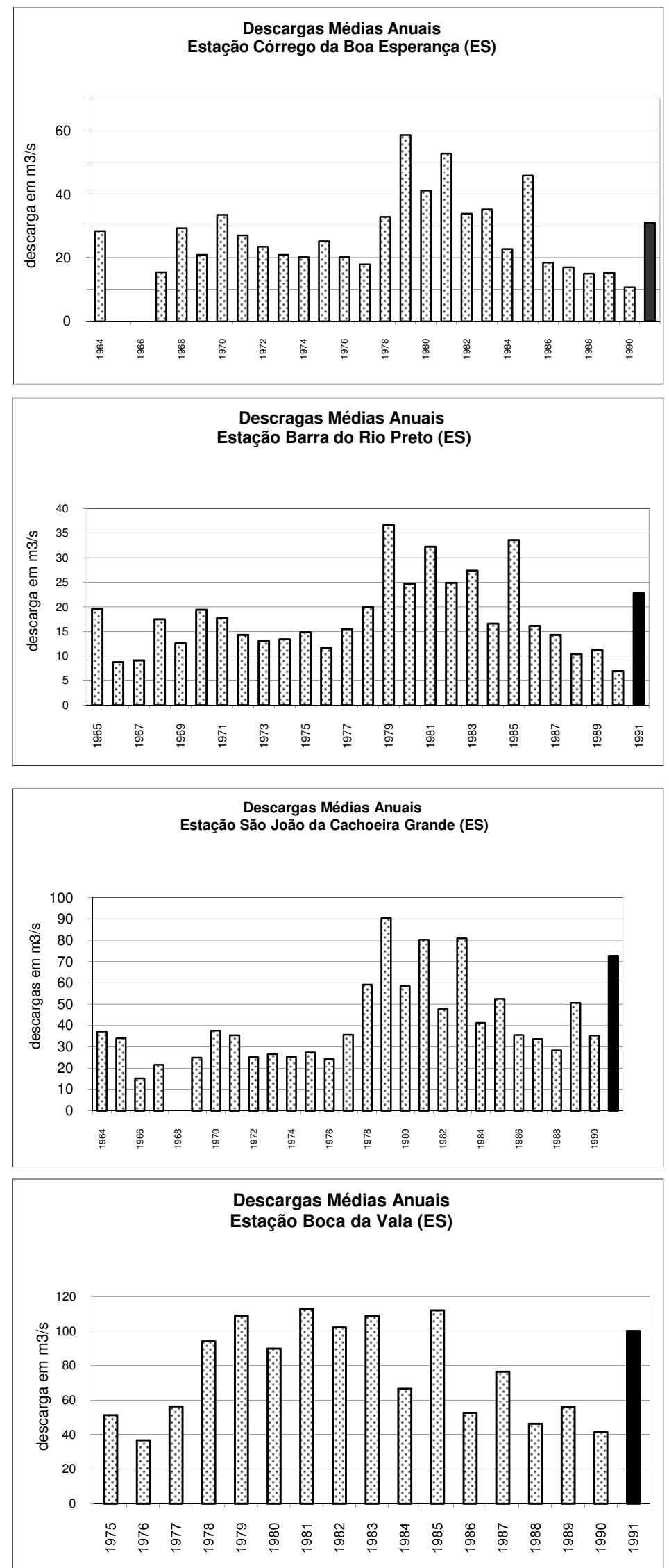

Figura 10 - Gráficos das estações fluviométricas localizadas na bacia do rio São Mateus. Fonte: Vale, 1999. 


\section{CONCLUSÕES}

Atualmente, decorrente dessa nova configuração, resta um banco de sedimentos no interior de uma laguna estuarina bem protegida do embate direto das ondas e do escoamento fluvial. Essa laguna apresenta profundidade em torno de 5,50 metros, resultante da migração do antigo canal principal para o sul. O banco de sedimentos está propiciando um acúmulo de sedimentos no seu entorno e favorecendo a fixação dos propágulos de mangue, que auxiliam, juntamente com seu sistema radicular, o aprisionamento dos sedimentos flúvio-marinhos.

Não obstante essas feições possam realmente ser correlacionadas com a precipitação e o escoamento ao longo da bacia, as mesmas não devem ser interpretadas apenas à luz da hidrologia ou da climatologia, uma vez que resultam de interações entre outros elementos inerentes às regiões estuarinas, que não podem ser desprezados, tais como os elementos oceanográficos como ondas, correntes e marés. Por outro lado, tão pouco se pode desconsiderar a presença e a atuação do homem como mais um elemento modificador das paisagens, cujas atividades por ele desenvolvidas, muitas vezes contribuem de forma decisiva no resultado de determinadas feições do relevo terrestre.

O setor 1 do estuário é um caso típico de progradação dos manguezais em direção à linha d'água. Durante muito tempo se atribuiu aos manguezais à capacidade de "construir terras" (DAVIS, 1940). Scholl (1968) afirma que os manguezais avançam apenas sobre terrenos que tenham sofrido sedimentação e estejam aptos para a colonização pelas plantas. A partir do momento em que os sedimentos são depositados na zona intermarés, os manguezais colonizam rapidamente esses terrenos, consolidando-os, podendo promover acreções posteriores (CARLTON, 1974; BLASCO et.al., 1990). O que se verifica na parcela 1 dos transectos 1 e 2 é uma acreção lenta e contínua de sedimentos dessa faixa da franja que se tornou disponível aos manguezais e estes a colonizaram, usando de suas características de $r$ estrategistas (CINTRON e SCHAEFFER-NOVELLI, 1992). Segundo Bird (1971) a extensão, pela qual os manguezais podem avançar em direção à linha d'água e promover a acreção vertical dos sedimentos, pode variar com a estrutura da comunidade de mangues. Ainda segundo o autor, os pneumatóforos de Avicennia sp. podem exercer taxas de acreção diferentes daquelas realizadas pelos propágulos e pelo sistema radicular de Rhizophora sp..

Vários trabalhos apontam a espécie Rhizophora mangle como a pioneira sobre as linhas de costas em processos de acreção (DAVIS, 1940; SAENGER e ROBSON, 1977). Todavia, nesse 
setor do estuário, a espécie que predomina é Laguncularia racemosa. Young e Harvey (1996) realizaram um importante trabalho sobre a taxa de acreção de sedimentos relacionada com a espécie Avicennia marina, na Nova Zelândia. Esse setor do estuário do rio São Mateus vem apresentando condições favoráveis aos experimentos realizados sob nossa orientação, semelhantes aos dos autores acima citados.

Observando a figura 2, percebe-se que o setor 2, onde localizam-se os transectos 3 e 4, constitui um remanescente de um trecho de manguezal que foi erodido pelo desvio do canal principal do rio São Mateus entre 1970 e 1997. Esse trecho, a despeito de localizar-se atualmente em um setor parcialmente protegido da laguna estuarina, encontra-se ainda sob forte erosão. O comportamento dos indivíduos localizados no início dessa franja é uma resposta ao processo de erosão atualmente verificado nesse trecho do estuário. Os indivíduos tombam ainda vivos, após terem seus sistemas radiculares expostos pela retirada dos sedimentos.

O setor 3, onde localizam-se os transectos 5, 6 e 7, em retrogradação, ocorre erosão muito semelhante à descrita por Semeniuk (1980) para a costa noroeste da Austrália. Segundo o autor, a erosão em lençol ocorre mais facilmente durante a maré morta, pois nesse período, a maior exposição da planície de maré à dessecação por evaporação, favorece o crescimento dos cristais de sais e a ruptura dos agregados de lama. Após 2 ou 4 semanas, a maré de sizígia rapidamente atravessa esse pavimento duro e lamoso, a água preenche as cavidades (tocas de caranguejo), os cristais de sais se dissolvem, a lama fluidifica-se e entra em colapso. Dentro de poucos minutos a lama torna-se uma suspensão densa, e o substrato, que não é facilmente lavado, erode rapidamente em função da inundação pela maré. A camada superior é removida à medida que a maré vazante carreia os sedimentos lamosos para o mar.

A exemplo do que ocorre na costa das Guianas (BLASCO et.al., 1990), em alguns trechos da foz do rio São Mateus também parece que a erosão começa e se intensifica a partir da morte dos mangues. De acordo com o autor, a morte dos mangues não é uma conseqüência da erosão costeira, mas sim uma causa, talvez a principal delas. Nesse sentido, reafirma-se o importante papel geomorfológico exercido pelos manguezais, cuja morte, natural ou antrópica, coloca em risco a manutenção da linha de costa. Bird e Ongkosongo (1980:4) afirmam que "The constructive and protective value of mangrove is often demonstrated 
where they have died back, or been cut down, exposing the substrate which is then rapidly eroded by waves scour."

Pelo que foi observado em campo, pode-se perceber que o processo de erosão no setor 3 ocorre do norte para o sul, tendo sido possível identificar e documentar os estágios descritos acima. O manguezal da franja, que até 1997 ainda resistia aos processos, foram substituídos por vegetação halófila-psamófila, sobretudo pelas espécies Alternanthera brasiliana, Blutaparon portulacoides, Hibiscus tileaceus, Acrostichum aureum, Allgoptera arenaria, dentre outras.

Nesse sentido, a concepção de análise dos ambientes onde ocorrem os manguezais proposta por Thom (1982), foi fundamental para o entendimento da gênese dos compartimentos de acumulação flúvio-marinhos ocupados pelos manguezais no estuário do rio São Mateus. Tal concepção sedimentou a compreensão do conceito de assinatura energética empregado para os ambientes dos manguezais, bem como fortaleceu a hipótese da apreensão do relevo através dos pressupostos teórico-metodológicos de Ab'Sáber (1969) e Ross (1992).

\section{REFERÊNCIAS BIBLIOGRÁFICAS}

ÁB'SÁBER, A. N. 1990. Painel das interferências antrópicas na fachada atlântica do Brasil litoral e retroterra imediata. In: II Simpósio de Ecossistemas da Costa Sul e Sudeste Brasileira. pp.1-27.

BIRD, E. C. F. 1971. Mangroves as land-builders. Victorian Nat., 88:189-197.

BIRD, E. C. F.; ONGKOSONGO, O. S. R. 1980. Environmental changes on the coasts of Indosesia. The United Nations University, Toquio. 52p.

BLASCO, F, SAENGER, P.; JANODET, E. 1990. Mangroves as indicators of coastal change. In: Catena 27, pp. 167-178.

BRASIL - MMA. 1996. Macrodiagnóstico da zona costeira do Brasil na escala da União. Brasília.

CARLTON, J. M. 1974. Land-Building and stabilization by mangroves. Environmental Conservations, vol. 1, n 4, pp. 285-294.

CINTRÓN, G.; SCHAEFFER-NOVELLI, Y. 1992. Ecology and management of New World mangroves. In: U. Seeliger (ed.) Coastal Communities of Latin America. Academic Press, San Diego, USA. pp.233-258. 
DAVIS, J. H. 1940. The ecology and geology role of mangroves in Florida. Carnegie Institute Washington Publication, 517: 307-409.

DEAN, W. 1997. A ferro e fogo. A historia e a devastação da mata atlântica brasileira. Ed. Companhia das Letras, São Paulo. 484p.

MARTIN, L., SUGUIO, K.; FLEXOR, J-M. 1993. As flutuações de nível do mar durante o Quaternário Superior e a evolução geológica de "deltas" brasileiros. In: Boletin IG-USP/ Publicação Especial, 15. 186p.

MUEHE, D. 1994. Geomorfologia costeira. In: Geomorfologia: Exercícios, técnicas e aplicações. (Orgs.) Sandra Baptista da Cunha e Antonio José Teixeira Guerra, Ed. Bertrand Brasil, Rio de Janeiro: 191-238.

ROSS, J. L. S. 1992. O registro cartográfico dos fatos geomórficos e a questão da taxonomia do relevo. Revista do Departamento de Geografia 6, FFLCH-USP, São Paulo. pp.17-30.

SAENGER, P.; ROBSON, J. 1977. Structural analysis of mangrove communities on the central Queensland coastline. Marine Research in Indonesia 18, pp.101-118.

SCHOLL, D. W. 1968. Mangrove swamps: geology and sedimentology. In: The Encyclopedia of Geomorphology,(ed.) Rhodes W. Fairbrigde. Reinhold Book Corp. N.Y. pp.683-688.

SEMENIUK, V. 1980. Mangrove zonation along an eroding coastline in King Sound NorthWestern Australia. Blakwell Scientific Publication, pp.789-812.

SNADEKER, S. C.; GETTER, C. D. 1985. Costas. Pautas para el manejo de los recursos costeros. Serie de Información Sobre Manejo de los Recursos Costeros, $\mathrm{n}^{\circ}$ 2, U.S. Agency for International Development, 286p.

SCHAEFFER-NOVELLI, Y.; CINTRÓN, G. 1986. Guia para estudo de áreas de manguezal. Estrutura, função e flora. Caribbean Ecological Research, São Paulo, 150p.

SUGUIO, K.; BIGARELLA, J. J. 1990. Ambientes fluviais. 2a edição, Ed. UFSC/UFPR. 183p.

THOM, B. G. 1982. Mangrove Ecology - A geomorphological perspective. In: Mangrove Ecosystems in Australia: Structure, Function and Management. B. F. Cluogh (Ed.). Australian National University Press. Camberra. pp. 3-18.

TUCCI, C. E. M. 1993. Hidrologia. Ciência e aplicação. Edusp/ABRH, São Paulo. 943p.

VALE, C. C.; FERREIRA, R. D. 1998. Os manguezais do Estado do Espírito Santo. In: IV Simpósio de Ecossistemas Brasileiros. Águas de Lindóia, São Paulo. vol. 1, pp.88-94.

VALE, C. C. 1999. Contribuição geográfica ao estudos dos manguezais com indicadores biológicos das mudanças geomórficas do estuário do rio São Mateus (ES). Dissertação de Mestrado. Departamento de Geografia. FFLCH/USP. 183p. 
YOUNG, B. M.; HARVEY, L. E. 1996. A spatial analysis of the relationship between mangrove (Avicennia marina var. australasica) physiognomy and sediment accreation in the Hauraki, New Zeland. Estuarine, Coastal and Shelf Science 42, pp.231-246. 